\title{
Micronutrient-Fortified Probiotic Yogurt
}

National Cancer Institute

\section{Source}

National Cancer Institute. Micronutrient-Fortified Probiotic Yogurt. NCI Thesaurus. Code C70677.

An micronutrient-fortified fermented dairy product with potential positive immunomodulatory activity. Micronutrient-fortified probiotic yogurt contains various micronutrients in addition to beneficial microorganisms, such as strains of Lactobacillus. Probiotic Lactobacillus strains have been shown to protect against gastrointestinal and urogenital infections, to moderate diarrheal episodes, and to increase CD4 T-lymphocyte counts. In immunocompromised subjects, micronutrient supplementation may also increase CD4 T-lymphocyte counts. 